\title{
When domains collide, boundaries shift
}

\author{
Stephen E. Arnold
}

In the ancient world, crossing a frontier triggered mixed emotions. Fear of the unknown or the threat of brigands outlined some voyagers' experience. There was excitement, evoked because of real or imagined adventures in crossing boundaries. Leaving the familiar world of one's home for a vacation in another country can, for some, heighten one's senses and stimulate the appetite for adventure.

\section{Boundaries: Real or imagined?}

Those engaged in the information industries today are also trying to cope with boundaries. Few of these feature hard lines of demarcation. When Caesar crossed the Rubicon, the symbolic action committed him to a course of action that rippled through the ruling elite of Rome. Entrepreneurs like Richard Rosenblatt, certainly no Julius Caesar, crossed from the land of MySpace.com into content production. His approach tapped individuals, often with little or no formal journalistic training, to create content. Thousands upon thousands of articles flowed from Demand Media into the firm's Web sites and on to his clients' Web sites. Though ignored by the "real" publishing community, Demand Media is poised for an initial public offering, introducing consulting services delivered by individuals who are not "real" consultants, and generating millions of clicks from Web sites like eHow.com and Cracked.com. Demand Media now is contemplating additional services which are similar to those offered by professional publishing companies and consulting firms. When I briefed a publishing company earlier this year, I mentioned Demand Media. I asked who was familiar with the firm. No one in attendance knew much about the company.

The issue of crossing a border, more specifically, the space between something well-known and something not-so-well-known is the focus of this essay. Of particular interest is the intersection of two different domains. Thinking broader than a college student taking her first trip to Paris, I want to explore what happens when digital spaces bump together. The boundaries of these intersections are in my opinion ripe with opportunities.

To give the inquiry some handholds, I will discuss the domains of traditional information and nontraditional production. In some ways, there is a significant financial stake in the boundary between these two domains. Each has its leaders and foot soldiers. Each has a method of working. Each has a mission. Each has a business model or models. What makes the intersection worthy of comment is that the collision of the traditional and non-traditional information worlds an important pivot point.

In the traditional versus non-traditional confrontations, I am not certain which "side" will win. Maybe neither will triumph? The costs of the collision may be so high that both sides fall, spent from the battle. Let's look at an example of domains in collision.

Before World War One, transportation was expensive. For most Americans and Europeans, horses and mules were the Chevrolets and Hondas of the era. By the end of World War One, automobiles captured 


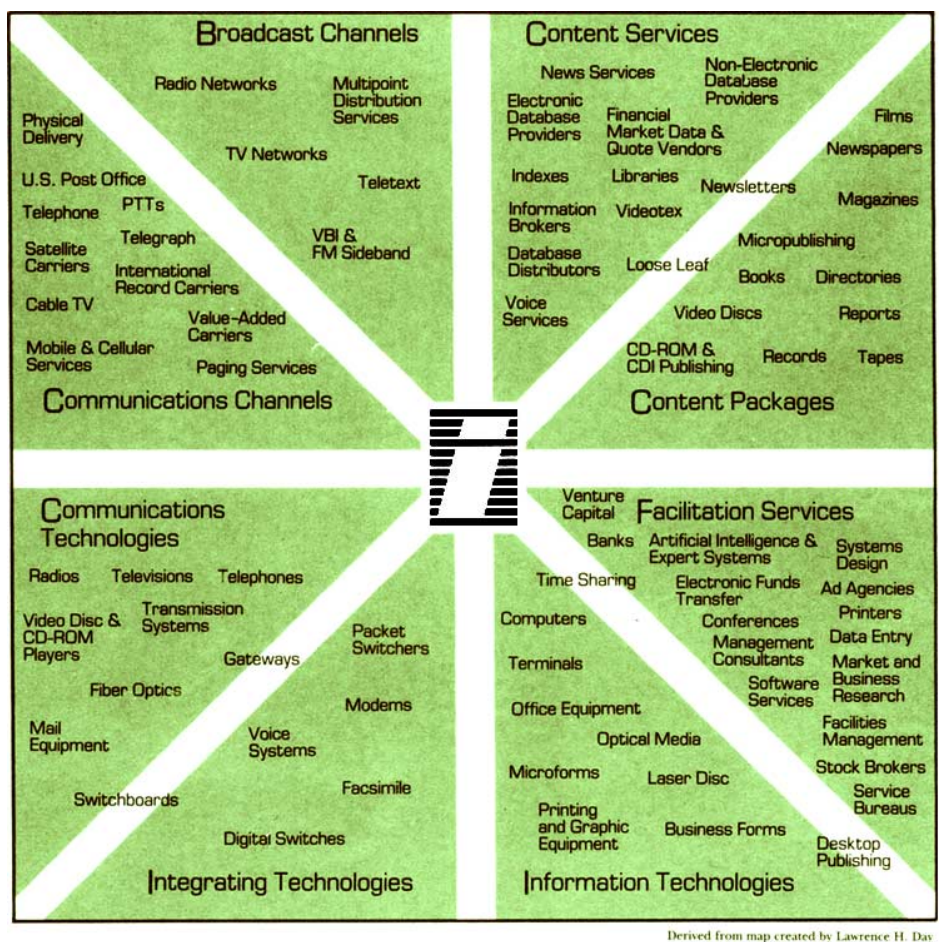

Fig. 1. (Colors are visible in the online version of the article; http://dx.doi.org/10.3233/ISU-2010-0619.)

the fancy of the public. With that shift, MBAs learned that buggy whip manufacturers should have been able to manufacture seat covers for the horseless carriage. According to business school lore, the bright and agile would thrive. The proprietors who did not adapt had to find their future elsewhere. Sounds good, does not it? Much of the US MBA cant has a similar lilt. The financial improprieties and the gasping economy make many aware of the shortcomings of MBA thinking. The domain of traditional financial conservatism died under the Hummmers driven by the top man at Bear Stearns or by the dare devil Bernie Madoff.

The point is that when domains collide - whether horses and automobiles or business methods based on trust with more facile and fluid approaches - unexpected consequences occur. The boundary at the intersection of domains that collide is one of uncertainty, opportunity and risk. Winners and losers often look at their fate and wonder, "What happened?".

Demand Media has been a winner. Let me use financial payout as a yard stick. Business Week magazine was the American version of the highly regarded Economist. Bloomberg purchased Business Week for about $\$ 5$ million. Associated Content, an information factory similar to Demand Media, sold to Yahoo for 15, maybe 18 times more than Business Week. That works about to $\$ 90$ million versus $\$ 5$ million. Associated Content and Demand Media produce bulk content for online consumption. If I measure quality in terms of dollars, is Business Week is a lower-value product when viewed in economic terms? Is the reasoned and sonorous writing of Business Week less successful than the crunchy, semi-professional outputs from hundreds of anonymous writers. The lesson from this transaction does not require a sleek, sharp-pencil MBA to explain. 


\section{Mapping the territory in 1980}

In the 1980s the original Information Industry Association (hereinafter, IIA) produced a diagram that attempted to capture the landscape of the information business. ${ }^{1}$ Here's a copy of the diagram from my files. I do not think this depiction is in wide circulation today. What the diagram communicates to me is that the world of electronic industry 30 years ago was fractured by fiefs and domains. The landscape of Information Technologies, Facilitation Services, Content Packages, Content Services, Broadcast Channels, Communications Channels, Communications Technologies and Integrating Technologies was a foreshadowing of today's fluid, chaotic datasphere.

The wording in this 30-year-old IIA diagram captures the paradoxes and tensions that disrupt organizations caught in multiple boundaries roiled by eddies and undertows of actions and reactions to electronic information. These labels with the words packages, services, channels and technologies are themselves difficult to define now. Legions of experts and academics work diligently to explain that there are distinctions within and among the concepts poorly captured in fuzzy jargon.

Let me give you one example. My cable television provider offers Internet access, motion pictures, telephone and electronic mail. The artificial boundaries in this diagram did not make sense in 1980, and in my opinion, the labels do not make much sense today. Some companies continue to act as though these domains are separate and distinct, but one can make a case for almost any position in our disinformationrich world. The reality is that users are different and may not understand some distinctions as they consume electronic content. The era of looking up information in a book on someone else's timetable has given way to a different method of anywhere-anytime working, playing and thinking.

For example, consider a group of middle-school girls. Perhaps one is your daughter or next door neighbor's child. Social interaction, social information and social learning orbit mobile devices. In this middle-school universe, different information physics apply. A mobile device can copy, share, and enable different behaviors and combinations of behaviors. The behaviors give rise to new opportunities which those outside the middle-school universe cannot easily understand. In the boundary between the traditional world of information and the fluid reality of electronic information, cultural and social change have taken place. The collision between domains began at least 30 years ago and the boundary condition is expanding rapidly, engulfing the smaller, older, less relevant domain.

Let me highlight three companies that have little in common with traditional information companies. What I find interesting is that each of these firms is having a bulldozer effect on print publishing, commercial information access, and rich media like music and video.

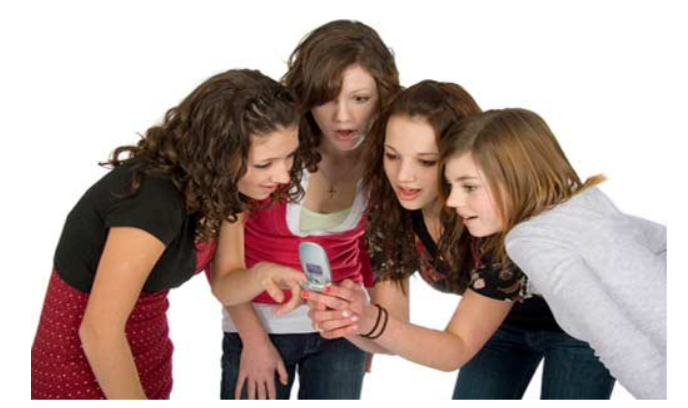

Fig. 2. (Colors are visible in the online version of the article; http://dx.doi.org/10.3233/ISU-2010-0619.)

\footnotetext{
${ }^{1}$ My recollection is that Paul Zirkowski, the president of the IIA, created the first version of this diagram.
} 


\subsection{Apple}

If we revisit the IIA diagram, Apple has rolled up or blended different segments of the information world as mapped in the 1980s. Keep in mind that Apple did not take actions that were stealthy or covert. The circles highlight the different sectors that Apple integrated.

As you know, Apple teetered on the brink of collapse until it developed an MP3 player, a product that acted like a catalyst for streaming content, rich media and online services such as eCommerce. Apple boss Steve Jobs recognized the opportunity and ran with it. Today Apple dominates a substantial portion of:

- Broadcast services, including rich media, streaming and time-shifted content.

- Hardware, which ranges from iPod music players to servers used by specialist firms. Apple also resurrected the failed tablet form factor, creating a product that some print publications see as a potential solution to the financial woes of some publishers.

- Content that spans audio books, digital books, free podcasts, for-fee programs and now software applications. One cannot move a document from the iPad to another computer without passing through the Apple iTunes' software. Cornelius Vanderbilt would have understood the importance of this chaining of activities.

- Online. Steve Jobs has figured out how to weave online into his money-spinning operation. Instead of making online a separate business, online has become a fabric woven into or epoxied on to the company's hardware and software products.

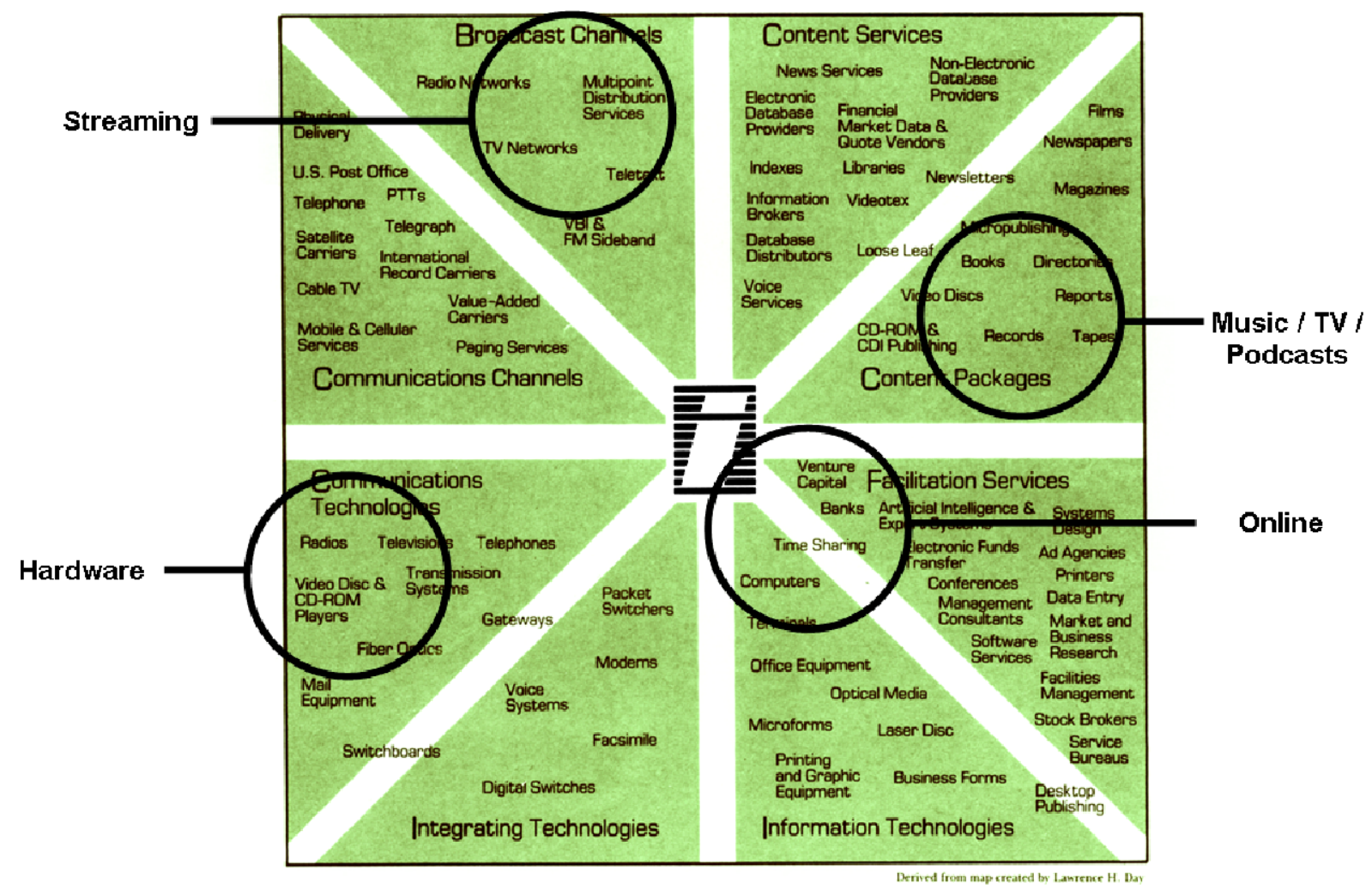

Fig. 3. (Colors are visible in the online version of the article; http://dx.doi.org/10.3233/ISU-2010-0619.) 


\subsection{Amazon}

The next example is Amazon. The company began as an online retailer of hard copy books and has now morphed into a digital Wal-Mart and a vendor of cloud computing services. The firm, run by a person whom some have characterized as the world's smartest person, moved from books to other products. The firm created a dedicated hardware device for reading electronic books, embraced streaming audio and video, and moved into such esoteric technical services as cloud computing. If we reference the IIA diagram, we can see that Amazon's business consists of:

- Brick and mortar installations; namely, the Amazon distribution centers and the company's physical infrastructure for its $\mathrm{S} 3, \mathrm{EC} 2$ and other hosted computing services.

- A streaming and downloading rich media services, a deal with archrival Netflix and the company's eBook hardware business. Recently Amazon began offering individual authors an easier method of publishing a book with Amazon and then selling the book on Amazon to Amazon's eBook customers.

- Amazon's products include hard goods like grocery store items and a range of digital products and services. Of particular importance to those in the traditional publishing and media industries is Amazon's steady expansion which seems to be moving toward Amazon's own cloud operating system.

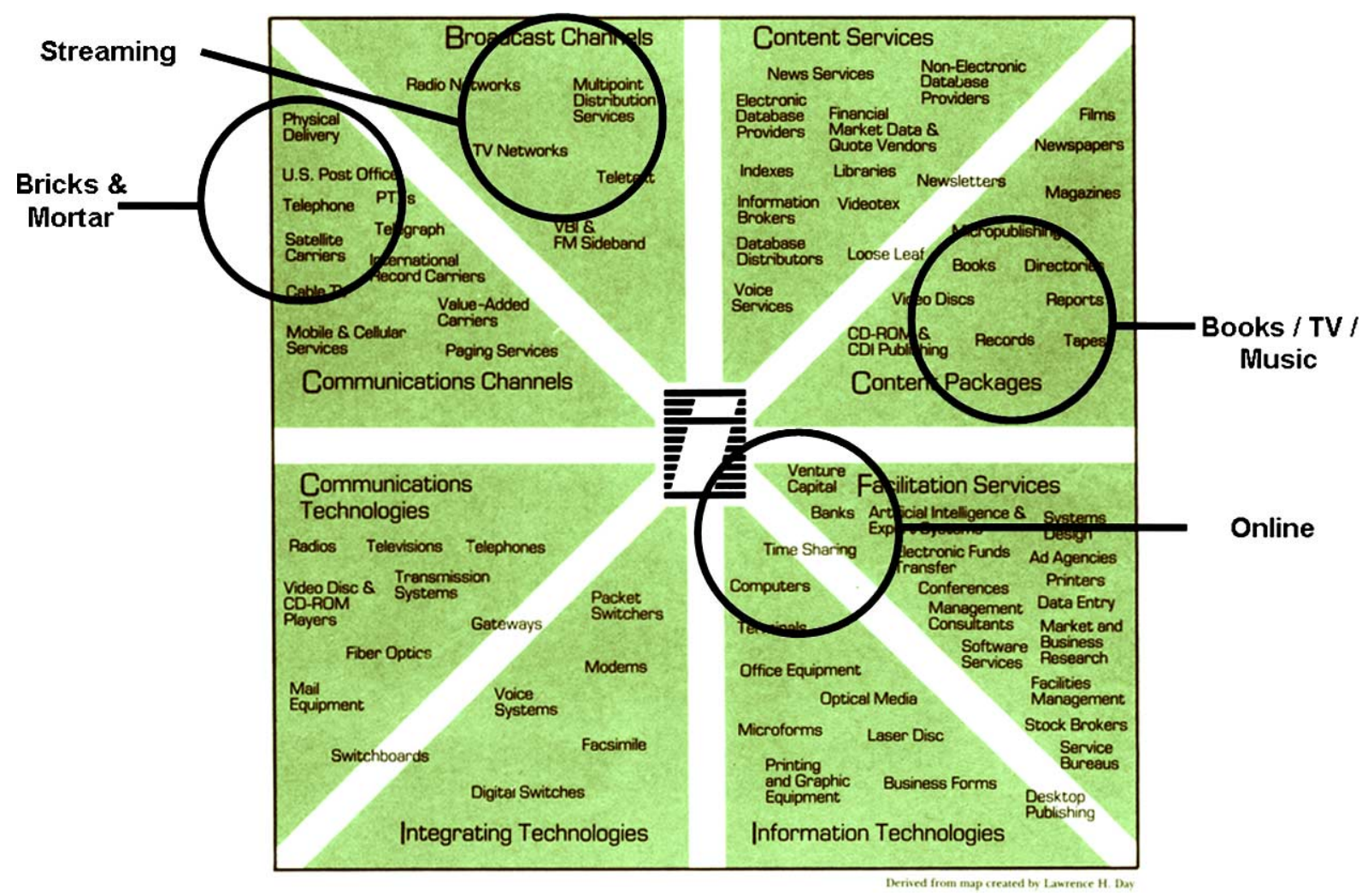

Fig. 4. (Colors are visible in the online version of the article; http://dx.doi.org/10.3233/ISU-2010-0619.) 
And, of course, online. Amazon embraced online, making it the foundation of the firm's business model. Keep in mind that Apple's foundation was hardware and Apple grafted online into the firm's hardwarecentric approach to revenue.

\subsection{Google}

And what about Google? If we look at the IIA diagram, we can identify what Google has done to become the dominant search and advertising giant. Like Amazon, Google was from its inception, an online play. Over the past decade, Google has openly and somewhat chaotically:

- Acquired telecommunications capabilities. As I write this, Google is in the process of conducting a test of a high speed Internet service. Using the company's own telecommunications infrastructure, Google may be transforming itself into a 21 st century version of the pre-Judge Green, monopolistic AT\&T.

- Rolled out streaming and time-shifted video services. In addition, Google has made a decision to hook its rich media services into a range of devices, including mobile handsets and set top boxes. Five years ago, few would have given Google much of a chance in its crazy quilt approach to products and services. Today, Google may be a significant impediment to Apple's rich media and hardware success. Incumbents stand on the sidelines and are not sure for whom to cheer.

- Invested in databases. Most people do not think of Google as a commercial database company. That may be an error. Google has directed resources into technology that takes publicly available content, processes it, generates metadata for those data and stores the data in a repurposeable form. The highly publicized Google Books project may get the spotlight, but the more substantive activities at Google involve databases - or what should be more properly described as dataspaces.

- Pushed into operating systems, applications and mobile devices. Google is behaving in a way that reminds me of Microsoft in the mid-1980s. Like Microsoft, Google seems compelled to dominate a number of different markets.

I have marked the IIA diagram to highlight the different products and services that Google used in building its $\$ 25$ billion in revenue.

\section{Lessons}

What do these three success stories tell us? For me, these are the lessons from the IIA diagram and the Amazon, Apple and Google examples.

First, each of these companies took separate domains from the IIA world view and mashed them together. The reason each of these companies remains disruptive is that competitors have not been as successful in putting domains together and managing the unpredictable behavior of the boundaries between them. If one thinks about the struggle some traditional publishers have had with online, the difference is that for the most part traditional publishers part have not been able to deal boundaries in flux. Amazon, Apple and Google have crossed boundaries. These three companies have assembled revenue-generating solutions by assembly. The three companies have used the older compartments like molecules. From well-known compounds, the three companies have created solutions which opened the door to different types of monetization opportunities. Reactive tactics like pay walls, legal actions, Hail Mary acquisitions and public policy pressure may not be enough to slow these juggernauts. 


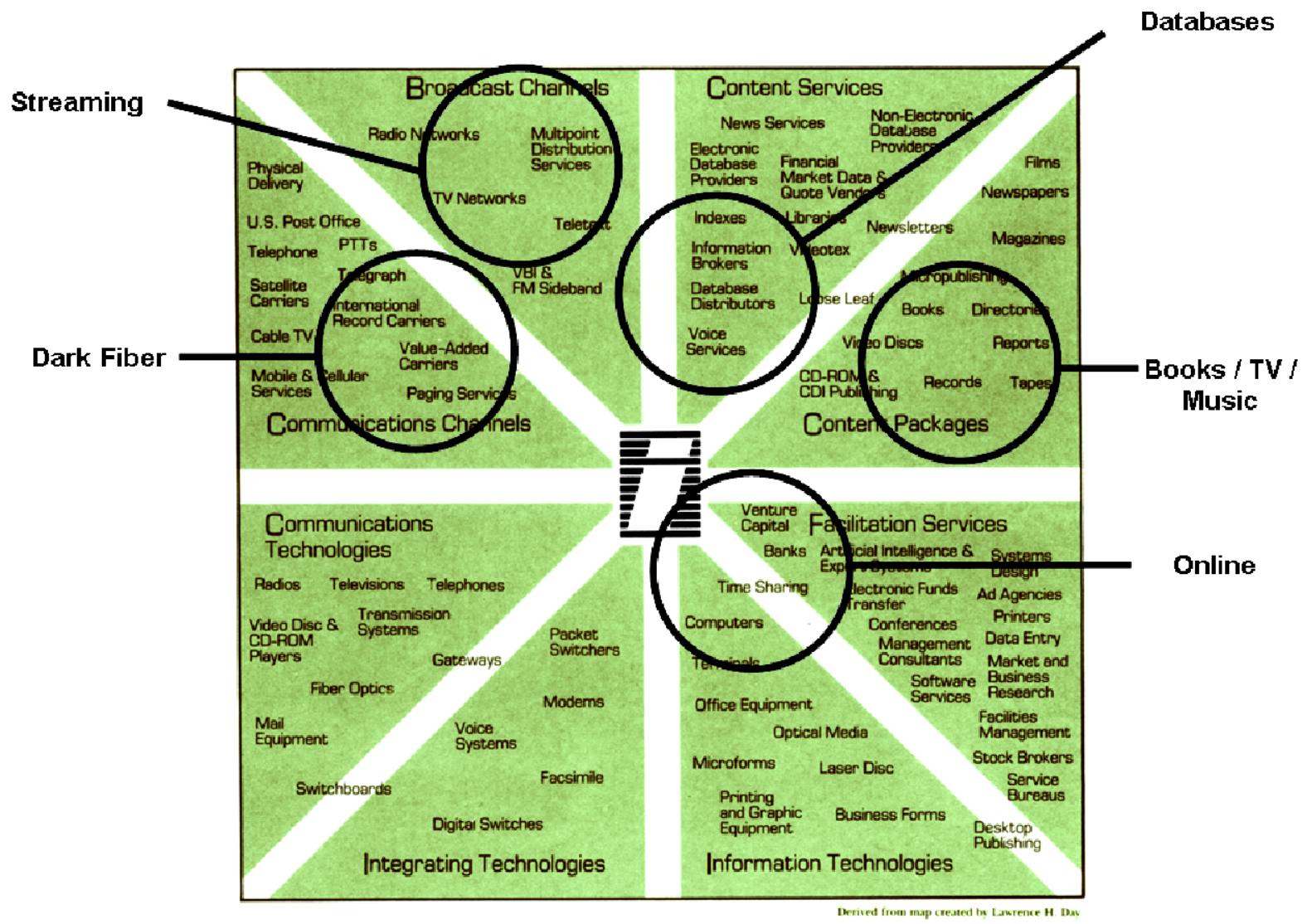

Fig. 5. (Colors are visible in the online version of the article; http://dx.doi.org/10.3233/ISU-2010-0619.)

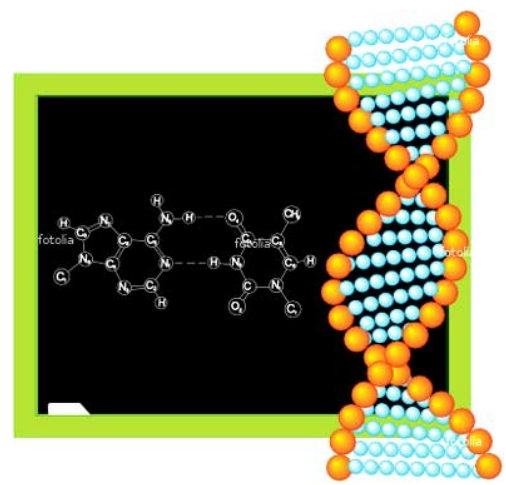

Fig. 6. (Colors are visible in the online version of the article; http://dx.doi.org/10.3233/ISU-2010-0619.)

Second, the business method has been to use online as infrastructure and technology as an enabler. Amazon, Apple and Google are very distinct organizations with different core competencies, but the secret to each company's success is at this time obvious, just very difficult to emulate. The me-too methods of traditional publishing, music and motion picture businesses do not translate exactly to the digital world. 
Finally, the creativity - the X factor perhaps? - of these three companies' executives has produced products and services that people want to buy. Apple has clever television advertisements, but did you buy your child's iPod or Macbook because of a TV ad? Do you use Google because of its cutting-edge marketing and stellar customer support? Do you buy books and cameras from Amazon because of its radio and television campaigns, and its reputation as a fashion trend setter?

I think the question becomes, "Why have traditional information companies been unable to deal with the boundary conditions when domains collide or, in some cases, are intentionally identified and baked in innovation's crucible?".

The DNA of these three companies may warrant more in-depth analysis in order to identify what constituents make the difference. Gene splicing may be one way for traditional information companies to adapt to the new boundary conditions that strike me as a standard feature of the modern business environment.

\section{Challenges or opportunities}

Let me highlight some of the obvious learnings I have gleaned from my work for governmental entities, not-for-profit organizations and commercial enterprises.

First, there is the problem of looking at a diagram like the confusing IIA representation, figuring out what is useful, and what is off kilter, and then assembling the pieces into a solution that generates revenue. The skills required range from common sense to technical aptitude, from market instincts to management effectiveness. The deeply conflicted behavior of traditional information companies. Traditional information companies use technology to reduce certain costs and shy from other technologies that do not fit into an established work process.

Second, there is the need to generate sustainable revenue. Traditional companies face some interesting financial challenges. Without cash, it is unlikely that traditional information businesses will have the resources to seize opportunities, fend off competitors and continue to operate with the overhead now on the balance sheets. Amazon, Apple and Google - despite their many shortcomings - are producing cash. No cash, may mean almost certain death.

Third, the notion of online is little more than an understanding that digital methods act like the every day items I used to hack together my home made teleprompter. (I am now producing audio and video programs to complement my surprisingly well received, free Web log.) These digital tools can shape opportunities. Used carelessly, new technology can sever a thumb or even worse, cut an artery. Another use for information technologies is to create new business methods. In short, technology makes possible substantive change in the nuts and bolts of a business. Simply applying digital methods to a flawed business process just costs more money and exacerbates other business problems.

Fourth, the markets are changing. Apple's iPad may be an ideal birthday gift for my father who will be 89. In addition, an Android phone from HTC may be just the ticket for a college student who wants Google $24 \times 7$. Amazon's Kindle may be exactly what a 55-year-old female who is hooked on books the Amazon way. Traditional information companies that roll out me-too products and then fail to innovate on a consumer product life cycle are likely to increase their costs and lose customers to those companies who "get it". The "it", of course, is the X factor that makes a winner a winner. No pundit or Madison Avenue advertising executive can deliver the $\mathrm{X}$ factor. Even through I used to work at Booz, Allen and Hamilton in its salad days, none of my then-colleagues could have done much for some of the information companies in today's economic climate. 
Fifth, the low barrier to entry for those who can program or surf intuitively on new technology creates a traffic jam of new products. At the summer 2010 computer show, more than two dozen tablet computers were announced. Most will fail, but there is similar non-linear growth in many sectors of the information industry. Online video is a particularly fecund area with innovations and roll outs coming as quickly as a disease vectors through a susceptible population.

Finally, the work is difficult. In 1979, I baked the phrase "Nothing worthwhile comes easy" into a Booz, Allen and Hamilton report. Today, I would modify the catchphrase to say, "Nothing worthwhile is any easier today". Traditional information companies often look for a slam dunk. Examples range from boosting prices of print subscriptions to specialty journals to legal maneuvering to block a competitor's attempted acquisition. Slam dunks are reactive and have unintended consequences in today's boundary conditions. Is it more prudent to innovate relentlessly, partner, and deliver products and services that customers and prospects crave? Should traditional information companies buy innovators to jump start unresponsive engines of commerce? Should those whipped to and fro in boundary conditions ride out the storm?

In my third Google study, Google: The Digital Gutenberg, I described technology in which Google has invested. ${ }^{2}$ At the time of the monograph's publication, Google was not making use of some of these technologies. Nevertheless, I thought it was a useful exercise to describe the latent capabilities of a Web search and online advertising system in terms of traditional information products, services, features and functions. One of the illustrations from the study shows how traditional paper-centric publishing works. If Gutenberg were alive today, he would recognize the broad outlines of the business he developed hundreds of years ago.

The salient features of this representation are three-fold. First, in this simplified representation, the publisher/producer is the catalyst and controlling force. The author writes, but the publisher/producer takes the information and makes it a business. Until recently, an author who tried to self publish was little more than a third-class wordsmith. To be a respected author, you needed a big name publisher or a publisher who made a great deal of money from the author's work. In today's world of domain collisions, the role of the publisher/producer is shifting into that of a curator or possibly a subsidized specialty.

Second, notice the process. The number of steps made the information creation method time consuming. When content had to be published quickly, the business model pivoted on advertising, multi-client studies, or as many different monetization methods as possible in the time window for the information's life span. Today I can create a blog post from my mobile device, click a button and the information is distributed via RSS to thousands of readers of my free Web log. The bewildering number of time-eating steps has been squeezed down to a tiny packet of actions that can take two or three minutes to complete. Information companies with resource-intensive, inefficient processes are riding in the Kentucky Derby carrying a bucket of Kentucky Fried Chicken and wearing a suit of armor. No winner for that thoroughbred owner.

Third, replacing a manual method with a computer method may not really reduce the overall friction inherent in the system and method. Most publishing companies with which I have worked spend quite a lot of money on technology. The problem is that the money does not deliver the type of lift that comes from using technology to create a new business method with a more progressive business model.

Some information companies perceive themselves as a major player in a particular business sector. I envision the situation in this way. The world has known boundaries and the environment behaves according to known and predictable laws. Think about Newtonian physics. The problem is that when

\footnotetext{
${ }^{2}$ Published by Infonortics Ltd. The eBook version of this monograph is available at http://www.infonortics.com.
} 


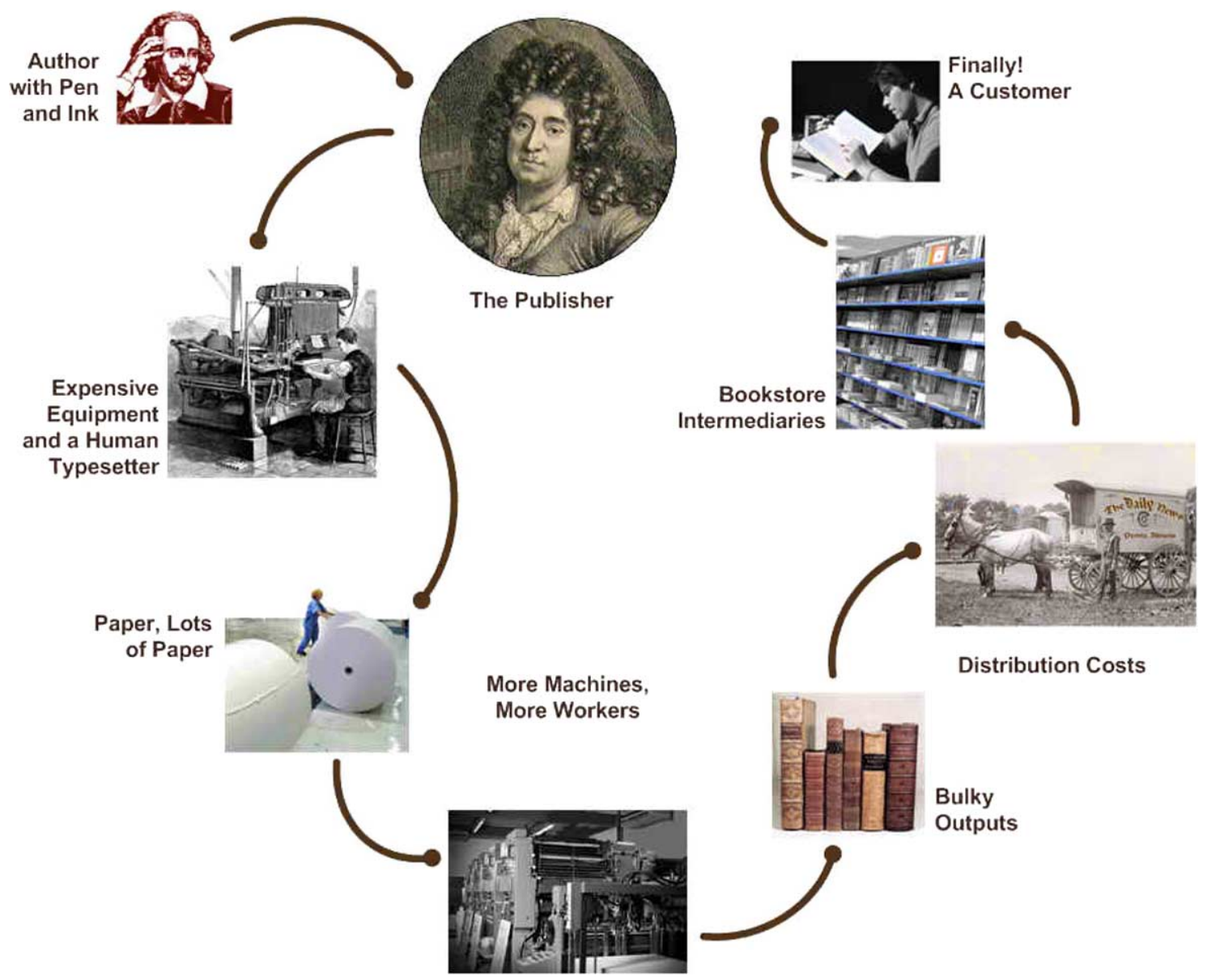

Fig. 7. (Colors are visible in the online version of the article; http://dx.doi.org/10.3233/ISU-2010-0619.)

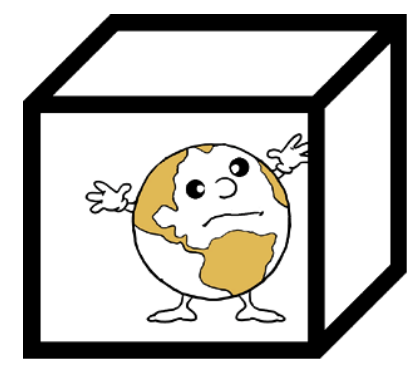

Fig. 8. (Colors are visible in the online version of the article; http://dx.doi.org/10.3233/ISU-2010-0619.)

domains collide and boundaries expand and contract, the world is much more complex space. Instead of having predictable laws and finite distances, information companies find themselves in a non-linear and unfamiliar environment. Newtonian physics no longer work as expected. Getting from point A to point B may not be a bright white line on solid black background. The situation can be visualized as one of those diagrams from a college math course avoided by anyone who wanted to be in a fraternity 


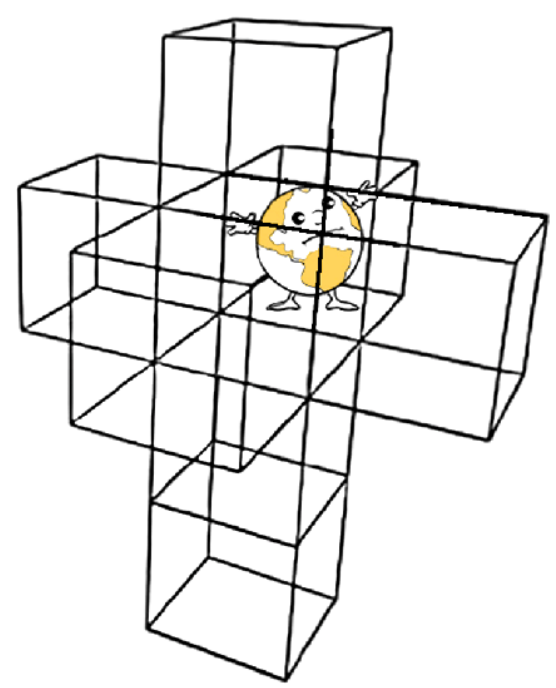

Fig. 9. (Colors are visible in the online version of the article; http://dx.doi.org/10.3233/ISU-2010-0619.)

or sorority and have a life sufficiently expansive to include a date, a trip to Florida on Spring Break, and some free time.

In today's world, the boundaries are not two dimensional or static. In fact, depending on point of view, the boundary may not exist. Viewed another way, the options are no longer Euclidean, the options occupy a space that behaves according to mathematical or physical principles that do not make sense. How many options exist in a hypercube? How can an object be in two opposite states at the same time? And more problematic, how can two separate "things" be connected without a physical wire hooking them together?

Information companies should be among the organizations most adept at dealing with these types of ambiguities. William Carlos Williams' poem about a red wagon is relevant in this context. The simplicity of the red wagon gives way to manifold complexity. Based on the financial plight of some information companies, writing about a red wagon and understanding the red wagon are different intellectual tasks. Today's digital world requires that information companies navigate these new, information spaces. Most do not, and I am not certain that some will have time to learn before money runs out, and the company has to close its doors for good.

I want to spend a few minutes looking at Google. In my forthcoming monograph, Google Beyond Text, I argue that Google has reached a peak and now faces some difficult challenges. ${ }^{3}$ Unless the company responds appropriately to these challenges, Google could become another Yahoo! or, even more disappointing, another Entopia or Lycos.

Google, in my opinion, should be viewed as an enabler. I use the phrase "digital Gutenberg" to connote that one can create content, distribute it and monetize the information's value on the Google platform. Google is a Web indexing company, a seller of advertising and an enterprise software company. Google offers more than 100 products and services. For information companies, Google is an opportunity. Google is a platform waiting to be used in creative, revenue-making ways. Google's business model offers a low-cost, flexible platform with a myriad of monetizing tools available essentially at low or no cost.

\footnotetext{
${ }^{3}$ Published by Intellas Press. Available in September 2010, http://www.intellas.com.
} 


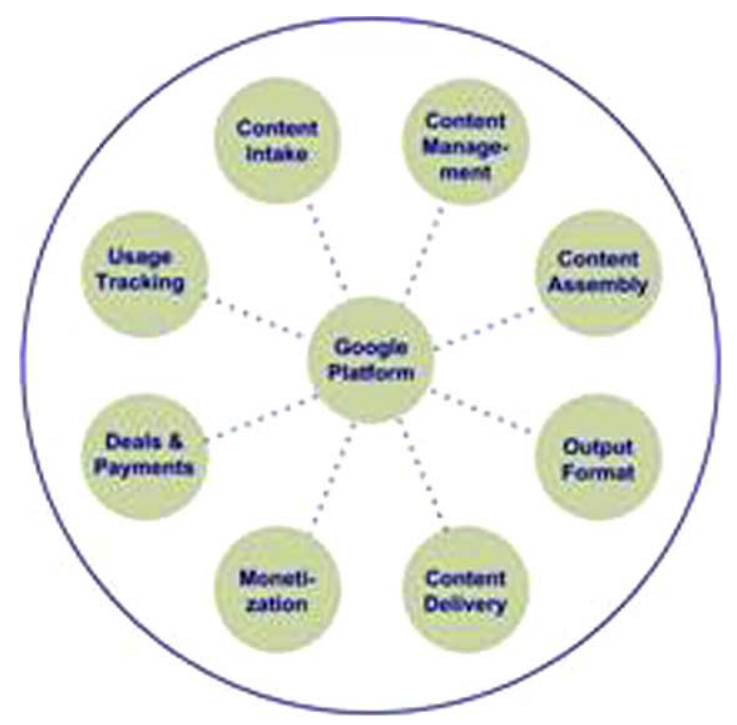

Fig. 10. (Colors are visible in the online version of the article; http://dx.doi.org/10.3233/ISU-2010-0619.)

Are information companies viewing Google in this way? No. Google has become the poster child from the Math Club for the problems the information industry faces. In my opinion, there are bigger problems than Google and those problems might be more effectively confronted by building on the Google-like platform.

If you do not want to work with Google, apply the same thinking to Amazon, Apple, Facebook, Rackspace, Twitter or any one of dozens of companies thriving in the boundaries the collision of domains has created. There is not a dearth of opportunities. The problem may be one of perception, confidence or technical know-how. The problem is, based on my research, not Google. After all, were the football players apprehensive about the Math Club members in intramural sports or in the cafeteria?

Let me conclude this discussion of domains in collision, boundaries and what I describe as "information physics" these observations. There is money to be made. Despite the dicey economy, opportunities abound. The trick is perceiving them and then acting with effect. Second, technology makes it possible to mash up, mix and match, repurpose and innovate at a higher rate of speed than at any other time in history. Going slow is okay when planning a trip, but once underway, the goal is to reach the destination. Jack Kerouac's approach is ill-suited to today's information highway. Third, Google - despite its public relations and marketing campaigns - is not going to "save" an industry or a company. If Google makes it possible for an industry or a company to generate revenue, my view is that one should seize it. Then look for other revenue-generating tie ups. Google is fueled by self-interest, just like many other companies. Watching and waiting will not work over the long term. Once an organization falls behind, catching up may be difficult. For evidence, consider Microsoft's multi-year effort to catch Google in Web search. In the collision of boundaries, technology can be a key enabler.

Original talk delivered in April 2010. This essay was written on June 18, 2010, from my notes for the original NFAIS members only lecture. 